$16^{\text {th }}$ International Conference on

AEROSPACE SCIENCES \& AVIATION TECHNOLOGY,

ASAT - 16 - May 26 - 28, 2015, E-Mail: asat@ mtc.edu.eg Military Technical College, Kobry Elkobbah, Cairo, Egypt

Tel : +(202) 24025292 - 24036138, Fax: +(202) 22621908

\title{
Dual-Thrust Rocket Motor with an intermediate Nozzle at the condition of higher boosting pressure than the sustaining pressure
}

\author{
Amr M. El-Nady ${ }^{1} \quad$ Ahmed M. Sarhan ${ }^{2} \quad$ Mohamed A. Al-Sanabawy ${ }^{3}$ \\ and \\ Mahmoud Y. Mohamed ${ }^{3}$
}

\begin{abstract}
:
Boost-sustain solid propellant rocket motors have been used to meet the demand for short and medium range tactical missiles. These motors obtain a wide variety of thrust-time profiles if the propellant characteristics and grain geometry are properly selected. These Dual Thrust Rocket Motors (DTRM) can have various designs; the DTRM with an intermediate nozzle is one design that yields a high boost-sustain thrust ratio with a stable operation. Under certain conditions, the flow through the intermediate nozzle at the start of motor operation can be reversed.

The present paper is intended to understand the phenomena and determine the operating parameters of DTRM with the reverse flow intermediate nozzle. In this study, a mathematical model describing the performance is derived from the main governing equations of internal ballistics (IB). Also, a set of experiments are conducted so as to inspect the details of the physics of such configuration DTRM. The experimental findings are utilized to validate the mathematical model.

Results of the theoretical and experimental investigation explain most of the IB characteristics that were not discussed before in the open literature.
\end{abstract}

Keywords: Internal Ballistics, Solid Propulsion, Dual Thrust Rocket Motor, Test Rocket Motor.

\section{Introduction:}

Compared with other rocket propulsion systems, solid propellant rocket motors (SPRM) are easier to manufacture, handle and store, and lighter in weight. In addition, SPRMs do not require maintenance for their entire shelf life and they contain less components so their reliability is higher. All these advantages make them superior to all other propulsion systems for various military applications.

Traditional designs of SPRM yield a monotonic thrust-time profile namely, either progressive, regressive, or neutral [1]. However, if the motor design, propellant characteristics, and grain geometry are properly selected, SPRM can provide a wide variety of thrust-time profiles. Dual (high-low or boost-sustain) thrust profiles have been developed to meet the demands for anti-tank guided missiles. DTRMs can have various designs; each of which has a range of operation depending on the resulting thrust ratio (boost-to-sustain thrust ratio) [2].

DTRM with an intermediate nozzle is a special design that is argued to yield a high thrust ratio with a stable operation. As shown in Fig. 1, DTRM consists of two chambers containing solid propellant grains separated by an intermediate nozzle and final main external nozzle.

$1 \quad$ Egyptian Armed Forces, a5_elnady@hotmail.com

2 Modern Academy at Maadi, Cairo, Egypt.

$3 \quad$ Egyptian Armed Forces. 


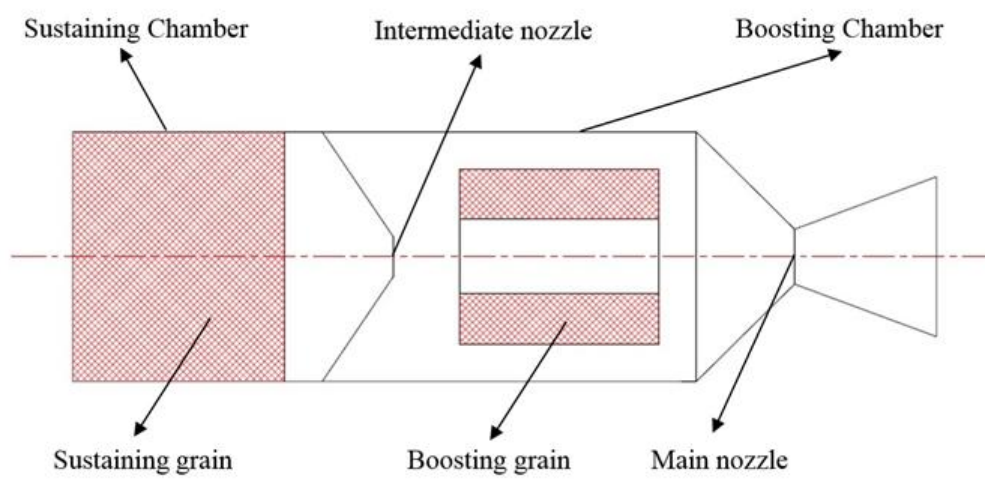

Figure 1 DTRM with an intermediate nozzle.

Both of the grains are ignited simultaneously starting the boost phase. The sustain phase follows as the booster grain burns out. During the boost (common function) phase, the combustion gas products flow through the intermediate nozzle and eventually through the main nozzle producing thrust. Depending on the internal flow conditions, the flow through the intermediate nozzle can be sonic, subsonic or reversed.

To the authors' best knowledge of the open literature, there has been no comprehensive study that investigated the phenomena in the DTRM with an intermediate nozzle. McFillin et al. [3] and Carrier et al. [4] focused on the internal ballistics of DTRM in the sustaining phase only. Only Manda [5] discussed the common operation of DTRM with an intermediate nozzle. However, the study was too concise to explain the rich details of this type of motors. This clear shortage of knowledge was the motivation behind the present study.

The objective of this paper is to understand the internal ballistics and phenomena of DTRM with reverse flow through the intermediate nozzle. In this study, a mathematical model describing the performance of DTRM in concern is derived from the main governing equations of IB. In addition, a set of experiments is conducted so as to reveal the details of the physics of this type of DTRM in both phases and assess the mathematical model validity.

\section{Theoretical Investigation:}

The developed mathematical model is based on satisfying the main governing principles of the gas thermo-fluid dynamics under the following assumptions [6]:

1. Combustion gases obey the perfect gas law.

2. Combustion gases are homogenous.

3. Steady state conditions.

4. Combustion gases flow is one dimensional, and isentropic.

5. Erosive burning and nozzle erosion are ignored.

6. Boosting and sustaining grains are made of the same propellant.

During the common function (boost phase), the pressure $\left(P_{s, b}\right)$ is initially lower than the pressure $\left(P_{b, b}\right)$ inducing a reverse gas flow occurs from the boosting chamber to the sustaining one through the intermediate nozzle where the pressure ratio obeys the following inequality:

$$
\left(P_{s, b}<P_{b, b}\right)
$$

By time, the pressure $\left(P_{s, b}\right)$ increases causing a reverse flow to diminish and eventually stops. In this case, It can be assumed that the sustaining pressure $\left(P_{s, b}\right)$ is equal to the boosting pressure $\left(P_{b, b}\right)$ at this moment. Practically, it means that the intermediate nozzle is ineffective and we deal with the SPRM as if it were a one chamber containing two propellant charges 
with different geometry common in the main outer nozzle. The pressure can be calculated under the following condition:

$$
\left(\frac{S_{b}+S_{S}}{A_{M}}>\frac{S_{S}}{A_{\text {int }}}\right)
$$

where $A_{M}$ and $A_{\text {int }}$ are the throat area of the main and intermediate nozzle, respectively. $S_{b}$ and $S_{S}$ are the burning surface areas of the boosting and sustaining grain, respectively. In this case, the pressure can be calculated directly from the following equation:

$$
P_{b, b}=\left(K_{I_{b s}} \cdot \rho_{s p} \cdot C^{*} \cdot r_{\circ}\right)^{\frac{1}{1-n}}=\left(\frac{S_{b}+S_{s}}{A_{M}} \cdot \rho_{s p} \cdot C^{*} \cdot r_{\circ}\right)^{\frac{1}{1-n}}
$$

where $K_{I_{b s}}$ is the blocking factor in both boosting and sustaining chamber. $\rho_{s p}$ and $C^{*}$, are the propellant density and characteristic velocity, respectively. $r_{\circ}$ and $n$ are the burning rate constant and pressure exponent, respectively.

On the other hand, during the sustaining phase, the pressures in both boosting and sustaining chambers; $P_{b, s}$ and $P_{s, s}$, respectively, can be simply calculated using the following relations:

$$
\begin{gathered}
P_{s, s}=\left(K_{I_{S}} \cdot \rho_{s p} \cdot C^{*} \cdot r_{\circ}\right)^{\frac{1}{1-n}} \\
P_{b, s}=\frac{P_{s, s} \cdot A_{i n t}}{A_{M}}
\end{gathered}
$$

Equations (3), (4) and (5) are used to estimate the combustion gas pressures in both boosting and sustaining chambers during both boost and sustain phases.

Finally, the thrust $(F)$ in both phases can be determined utilizing the following relation:

$$
F=P_{t} \cdot A_{M} \cdot \Gamma \cdot \sqrt{\frac{2 k}{k-1} \cdot\left(1-\left(\frac{P_{e}}{P_{t}}\right)^{\frac{k-1}{k}}\right)}+A_{e}\left(P_{e}-P_{a}\right)
$$

where $\Gamma$ is function of specific heat ratio $k, A_{e}$ is the main nozzle exit area, $P_{t}$ and $P_{e}$ are the total and exit pressures of the combustion gases, respectively, and $P_{a}$ is the atmospheric pressure.

\section{Experimental Investigation:}

The objective of this experimental investigation is twofold. On the one hand, to comprehend the physics of internal ballistics taking place in a real DTRM. On the other hand, results of experiments are implemented to assess the validity of the developed mathematical model. For the latter objective, more than four experimental tests have been conducted for the operation of DTRM with reverse flow intermediate nozzle. The burning law for the selected propellant has been predicted based on experimental measurements and thermochemical calculations. 


\subsection{Characteristics and burning law of the used propellant:}

A Double-Base (DB) solid propellant is utilized in the experiments. The burning law of the used propellant was determined experimentally using a standard static firing test motor and was eventually found to have the form:

$$
r=0.0005113 . e^{0.00345\left(T_{s p}-20\right)} \cdot P_{c}^{0.183}
$$

where $T_{s p}\left[{ }^{\circ} \mathrm{C}\right]$ is the propellant temperature, $P_{c}[\mathrm{~Pa}]$ is the pressure of the combustion gases, and $r[\mathrm{~m} / \mathrm{s}]$ is the burning rate.

\subsection{The proposed test rocket motor:}

In the literature and in practice, there exist well-defined standard test motors for conventional, single thrust solid propulsion applications. However, as far as dual-thrust applications are concerned, there exist no specific definitions for a standard test motor in the open literature. This motivated the authors to develop a proposed test rocket motor TRM for applications involving DTRM with intermediate nozzle.

The preliminary design for this proposed TRM should include 4 main blocks which are the sustaining chamber, the intermediate nozzle, the boosting chamber, and the main nozzle.

To reach the final detailed design of the TRM, in addition to technical and practical considerations, a number of constraints has been specified:

1. Utilizing available on-shelf raw materials,

2. Satisfying maximum and minimum operating pressures,

3. Satisfying the reverse flow through the intermediate nozzle.

4. Providing neutral thrust in both boost and sustain phases.

The detailed design of the TRM is obtained as shown in Fig. 2. The boosting charge is made as tubular grain inhibited from the ends whereas the sustaining charge is a cigarette burning grain. Motor ignition is undertaken using one igniter placed in the sustaining chamber (upstream of the intermediate nozzle). A secondary igniter charge is placed downstream of the intermediate nozzle to insure ignition of the boosting grain.

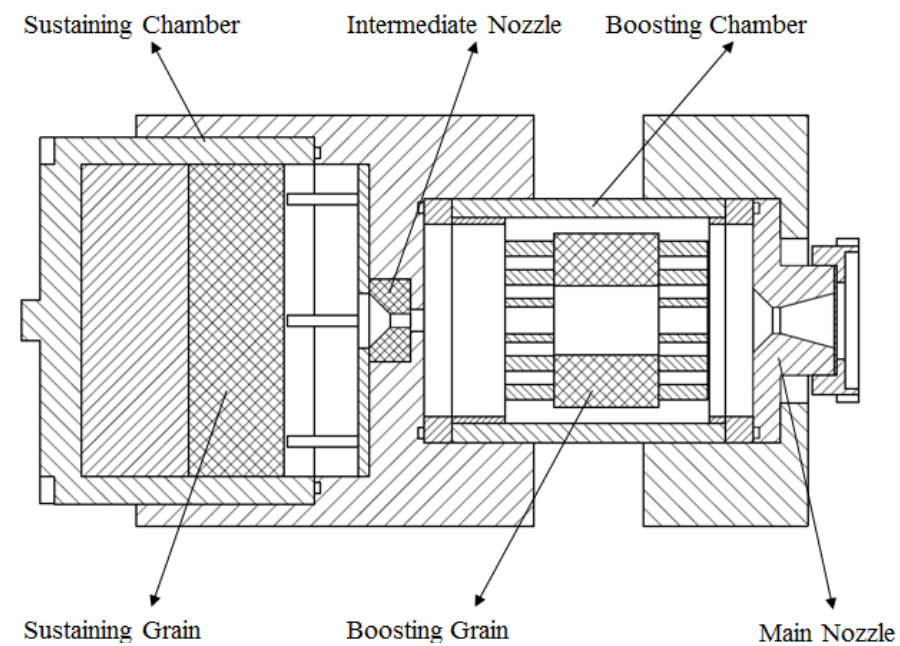

Figure 2 Design drawing of TRM 


\subsection{Design of static firing tests:}

Horizontal test stand along with a set of measuring instruments were used in examining the TRM. The main function of this test facility is to measure the main loads acting on the TRM which are the internal pressure and the axial thrust force.

Four different main static firing tests were planned. Prior to performing these main tests, two preliminary static firing tests were conducted namely, a function static test and a sustaining static test. All these six tests were conducted in the same nominal environmental conditions namely, temperature of $20^{\circ} \mathrm{C}$ and pressure of 1 bar. Description and objective of each of the six tests are summarized in Table, 1 .

Table 1 Plan of static firing tests

\begin{tabular}{|c|c|c|c|}
\hline Test & No. & Description & Objectives \\
\hline Function static test & 1 & $\begin{array}{l}\text { TRM fully equipped with } \\
\text { propellant charges without } \\
\text { measurement of any internal } \\
\text { ballistic parameters }\end{array}$ & $\begin{array}{l}\text { To verify the safe operation } \\
\text { and that the TRM will } \\
\text { withstand the ballistics, } \\
\text { structural and thermal } \\
\text { stresses }\end{array}$ \\
\hline Sustaining static test & 1 & $\begin{array}{l}\text { TRM containing sustaining } \\
\text { grain only while the boosting } \\
\text { chamber is empty. All sensors } \\
\text { are connected and are } \\
\text { functioning during the test }\end{array}$ & $\begin{array}{l}\text { To verify the propellant } \\
\text { internal ballistic parameters. } \\
\text { To check safety and } \\
\text { measurement possibilities. }\end{array}$ \\
\hline Main static tests & 2 & $\begin{array}{l}\text { TRM fully equipped with } \\
\text { propellant charges. All sensors } \\
\text { are connected and are } \\
\text { functioning during the test. The } \\
\text { test is repeated to assess the } \\
\text { measurements }\end{array}$ & $\begin{array}{l}\text { To validate the theoretical } \\
\text { model condition }\left(P_{s, b} \ll\right. \\
\left.P_{b, b}\right) \text { where strong reverse } \\
\text { flow is expected. }\end{array}$ \\
\hline Modified static tests & 2 & $\begin{array}{l}\text { Minor modifications to the } \\
\text { grains and nozzles dimensions } \\
\text { of the basic test of the sonic } \\
\text { case. }\end{array}$ & $\begin{array}{l}\text { To demonstrate the upper } \\
\text { limit of the TRM operation } \\
\text { by making the pressure in } \\
\text { the sustaining chamber } \\
\text { slightly lower than and } \\
\text { almost equal to the pressure } \\
\text { in the boosting chamber. }\end{array}$ \\
\hline
\end{tabular}

\section{Results and Discussions:}

\subsection{Sustaining phase static test:}

The results (pressures and thrust time curves) of the sustaining static test case are presented in figures 3 and 4, respectively.

In fig. 3, the sharp pressure rise at the start of motor operation is caused by the ignition charge located in the sustaining chamber reaching a value of about 226 bar. The gases produced by sustaining grain in the ignition phase expand through the intermediate nozzle to a much lower value of about 31 bar that is sensed in the boosting chamber with time lag of about 0.035 seconds. After ignition phase, the sustaining grain starts burning yielding a combustion pressure of about 103 bar (similar to theoretical approach) that is reduced via expansion to about 21 bar in the boosting chamber (less than the theoretical approach). The sustaining chamber pressure increases gradually to a value of about 116 bar at 1.3 seconds of the motor function time and drops gradually afterwards until it reaches a value of about 68 
bar. The tail-off phase of the pressure-time curves starts at about 2.8 seconds taking approximately 0.3 seconds.

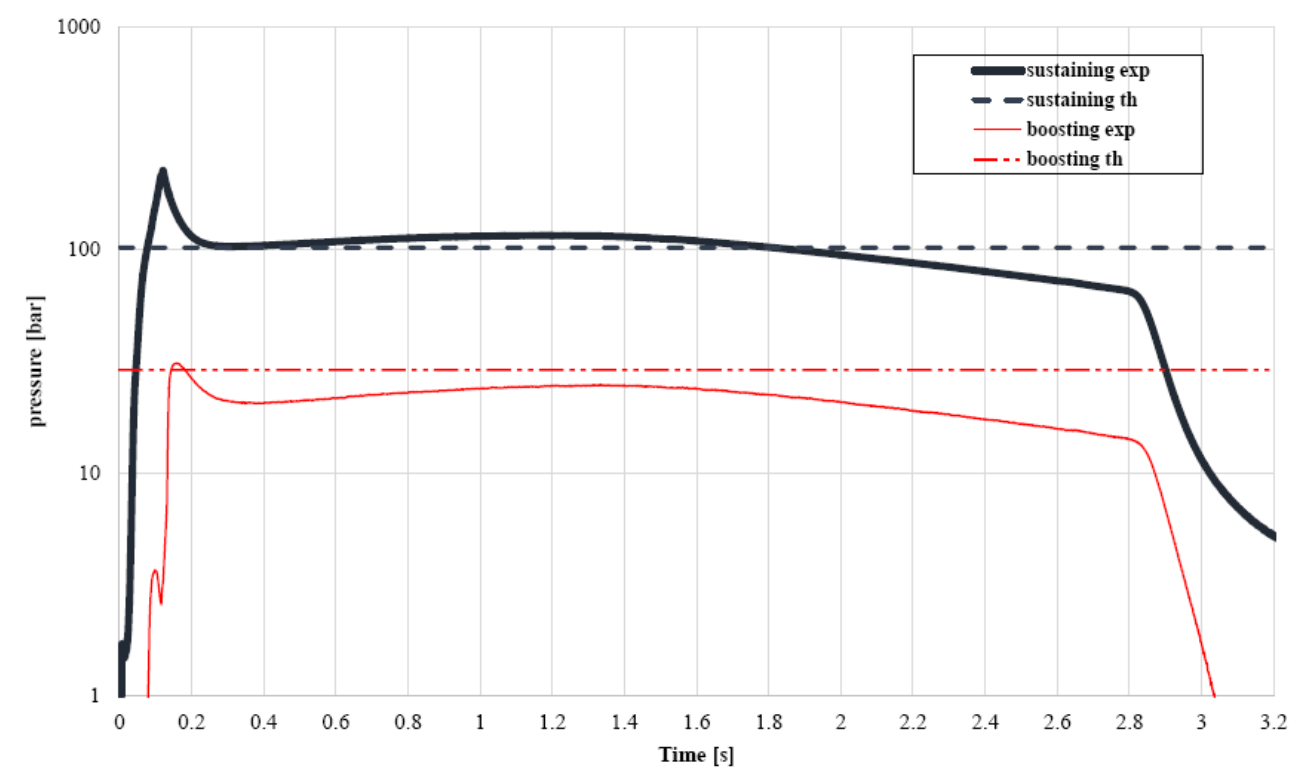

Figure 3 Pressure-time curves of the sustaining static test

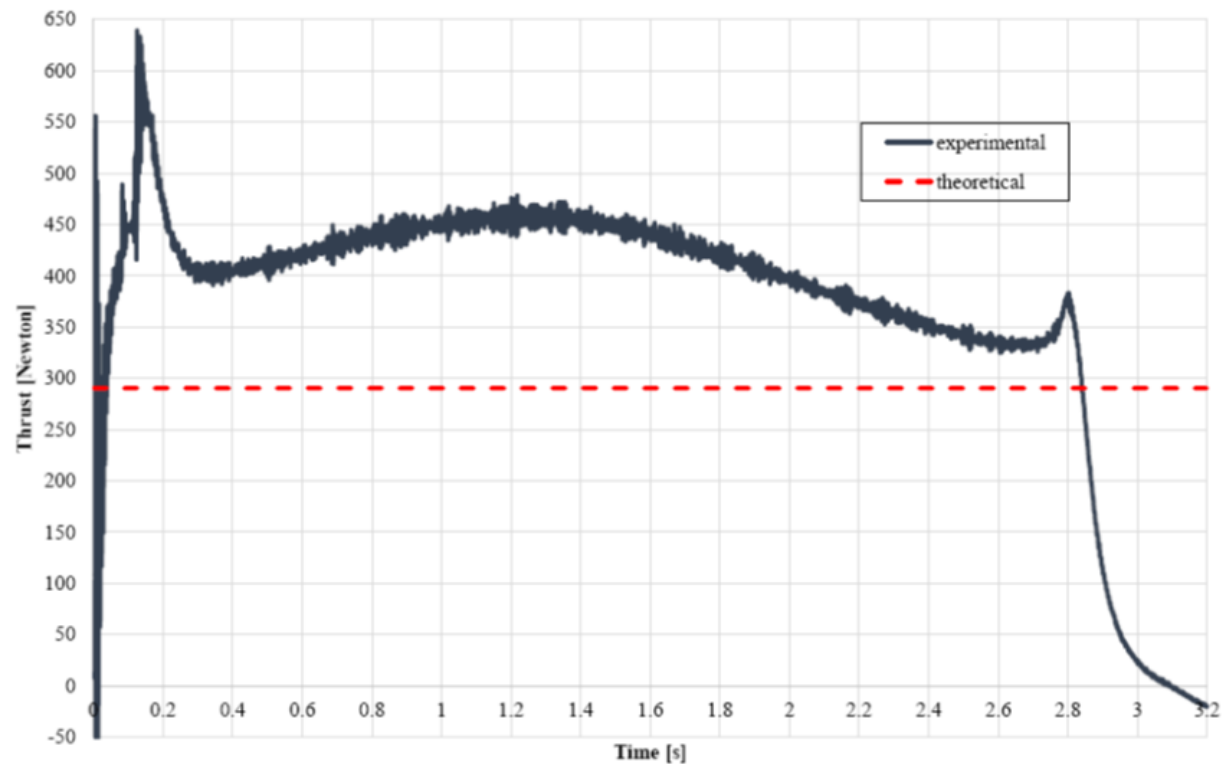

Figure 4 Thrust-time curve of the sustaining static test

The significantly high value of about 230 bar in Fig. 3 may indicate an excessive amount of the igniter charge. Immediately after ignition, the end-burning grain in the sustaining chamber is expected to yield a constant pressure over its operation time as introduced before. However, a deviation from this trend is witnessed in the present test. The initial slight increase in the sustaining chamber pressure may be caused by the convexity of the burning surface taking place during its regression. The metallic walls of the chamber are heated up due to existence of hot gases. These hot walls may have the role of increasing the burning regression rate at the parts of the propellant adjacent to the walls. Also imperfections in grain outer surface insulation due to convexity may explain the slight increase in sustaining chamber pressure. 
On the other hand, as the grain surface burns back, the free volume inside the chamber increases, the chamber pressure tends to decrease, and the burning rate drop down. The convexity of the burning surface is assumed to yield a zone of sliver which increases the free volume and reduces the actual burning surface. The combined effect of these factors may explain the gradual but significant drop (about 48 bar) in the sustaining chamber pressure towards the burnout of the grain.

Immediately after burnout, the accumulated gases exit the sustaining chamber causing the sharp drop in the chamber pressure. The intermediate nozzle has the continuing role of throttling the exhaust gases into the boosting chamber where they expand to a much lower pressure. The time lag of about 0.035 seconds can be addressed throughout the motor operation time.

Comparing the approaches (experimental and theoretical) in Fig. 3, it can be seen that the average experimental sustaining chamber pressure almost coincides with the theoretical one while the experimental boosting chamber pressure is always less than the theoretical one. This may be owed to three factors. On the one hand, the losses in the TRM are not accounted for in the underlying isentropic assumptions of the theoretical model. This isentropic assumption leads to shorter burning times for the theoretical approach than those in the experimental one. On the other hand, convexity of the surface of burning may cause the slight increase in pressure that appears in the experimental reading. More importantly, the location of the pressure transducer in the boosting chamber may not be the proper one to measure the correct boosting pressure. An explanation of this aspect is attempted below.

Due to design constraint, the pressure transducer port inside the boosting chamber is located in the shadow of the jet exiting the intermediate nozzle as shown in fig. 5. The gas flow in the vicinity of the port may generate a vortex structure, leading to lower pressure.

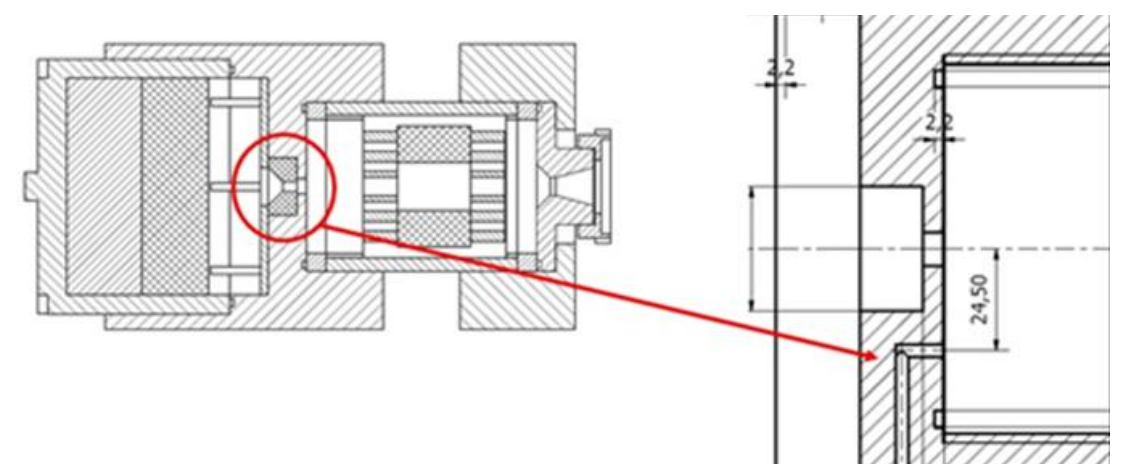

Figure 5 Location of the pressure transducer in boosting chamber

In fig. 4, the thrust follows fairly the same trend of boosting chamber pressure. The persisting rebels in thrust curve and the sudden spire at the onset of tail-off phase (at about 2.8 seconds) may all be owed to improper fixation of the TRM on the test bed. The sustaining thrust values (average $395 \mathrm{~N}$ ) are higher than the designed theoretical ones $(250: 300 \mathrm{~N})$. Further analysis showed that this discrepancy maybe owed to two factors.

On the one hand, the transducer that is used in the experiments with upper limit $10000 \mathrm{~N}$ has $1000 \mathrm{~N}$ limit for first-order measurements or $500 \mathrm{~N}$ limit for second-order measurements. So the designed sustaining thrust lies in the nonlinearity zone for the used transducer. On the other hand, the fixation of the TRM on the test bed followed by the over preloading value is the other cause for increasing the experimental sustaining thrust than the theoretical one. Normally, the preloading value should not exceed $30 \%$ of the expected thrust 
to be measured. This rule is violated due to the available fixation technique. This is more pronounced in the sustaining phase where the maximum expected thrust is about $300 \mathrm{~N}(30 \%$ of the preloading value). The available facilities dictate using a pressurized air circuit having a clear leakage in the circuit. To overcome this leakage, over preloading value $(0.7: 0.92 \mathrm{v}$; equivalent to $900 \mathrm{~N}$ ) ought to be applied.

It should be noted that, since the present experiments deal with DTRM, rules for the presetting loads would have been violated especially during the sustaining phase in all cases. In fact, designing a presetting technique that automatically changes the presetting load value may be unattainable.

\subsection{Main static tests:}

A basic firing test is carried out for the designed TRM and is repeated to confirm and assess the results. Dimensions of grains and nozzles are listed in Table 2, followed by the pressure and thrust time curves for each test (figures 6 to 11). For the sake of comparison, the corresponding theoretical results for the basic and repeated tests are plotted in these figures.

Table 2 Grains and nozzles dimensions for DTRM

\begin{tabular}{|l|c|}
\hline \multicolumn{1}{|c|}{ Name } & Value \\
\hline Sustaining grain (outer diameter x its length) $[\mathrm{mm}]$ & $110 \times 25$ \\
\hline Boosting grain (outer diameter x inner diameter x its length) $[\mathrm{mm}]$ & $63.6 \times 24.6 \times 136$ \\
\hline Main nozzle (throat diameter $\mathrm{x}$ exit diameter) $[\mathrm{mm}]$ & $9.37 \times 20$ \\
\hline Intermediate nozzle (throat diameter) $[\mathrm{mm}]$ & 4.98 \\
\hline
\end{tabular}

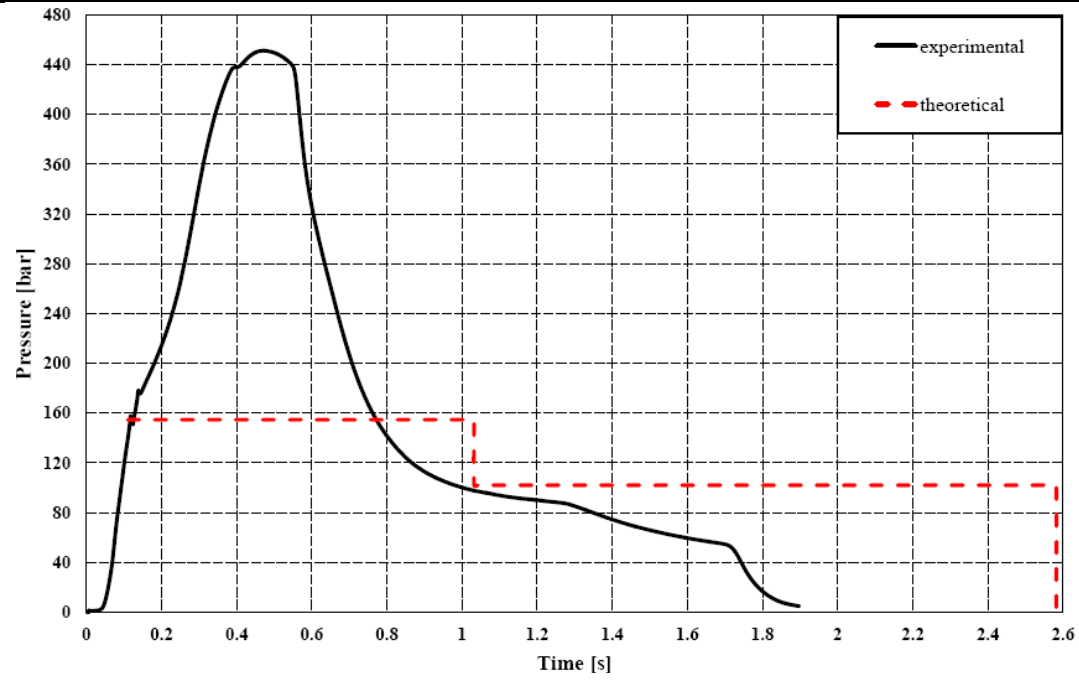

Figure 6 Sustaining chamber pressure-time profile for the main firing test 


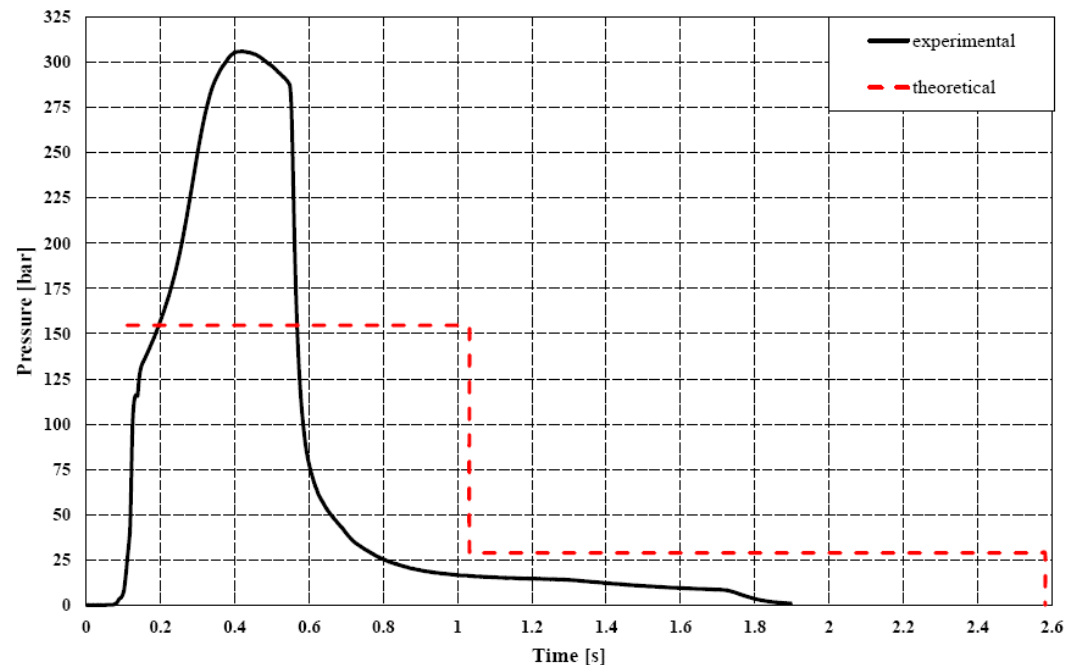

Figure 7 Boosting chamber pressure-time profile for the main firing test

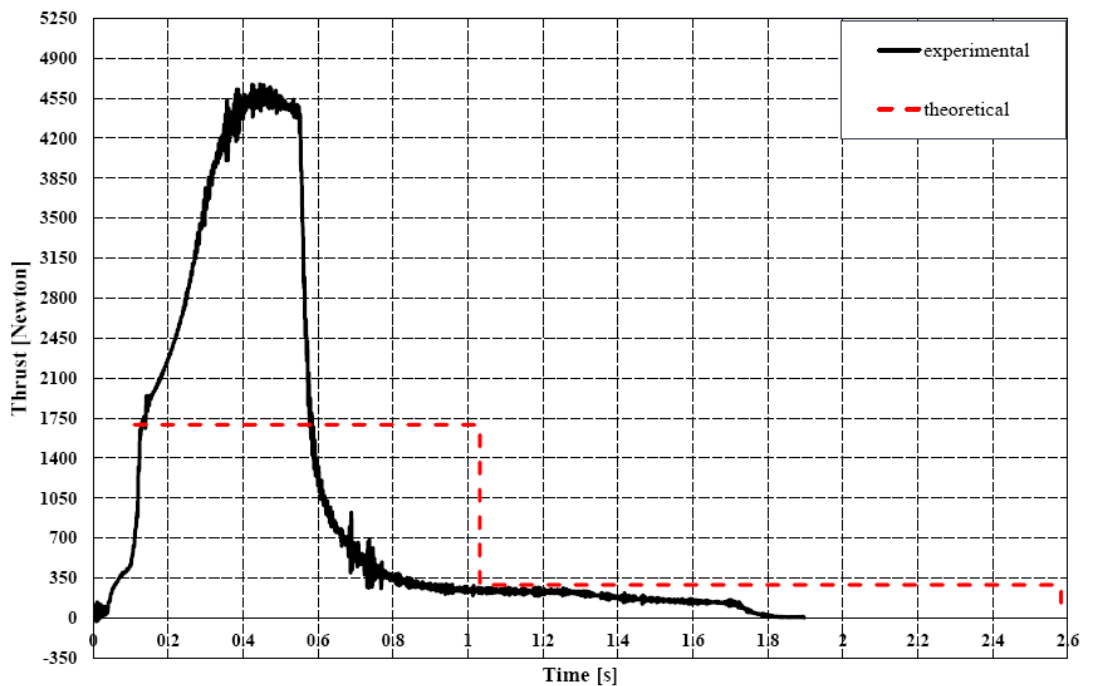

Figure 8 Thrust-time profile for the main firing test

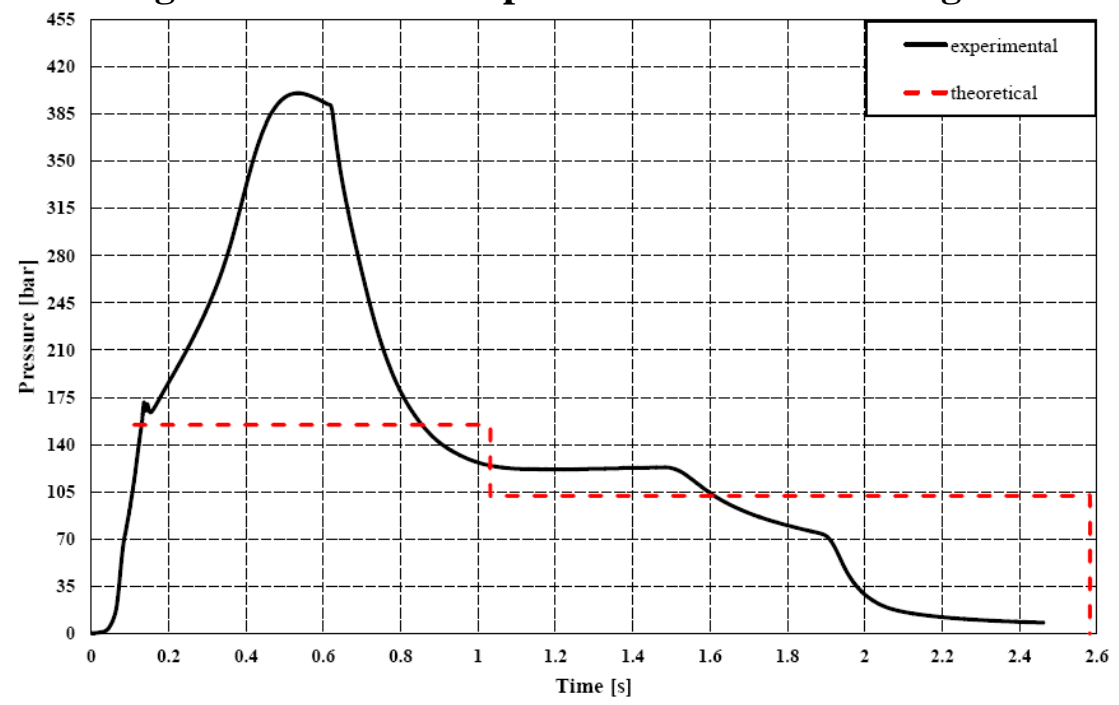

Figure 9 Sustaining chamber pressure-time profile for the repeated firing test 


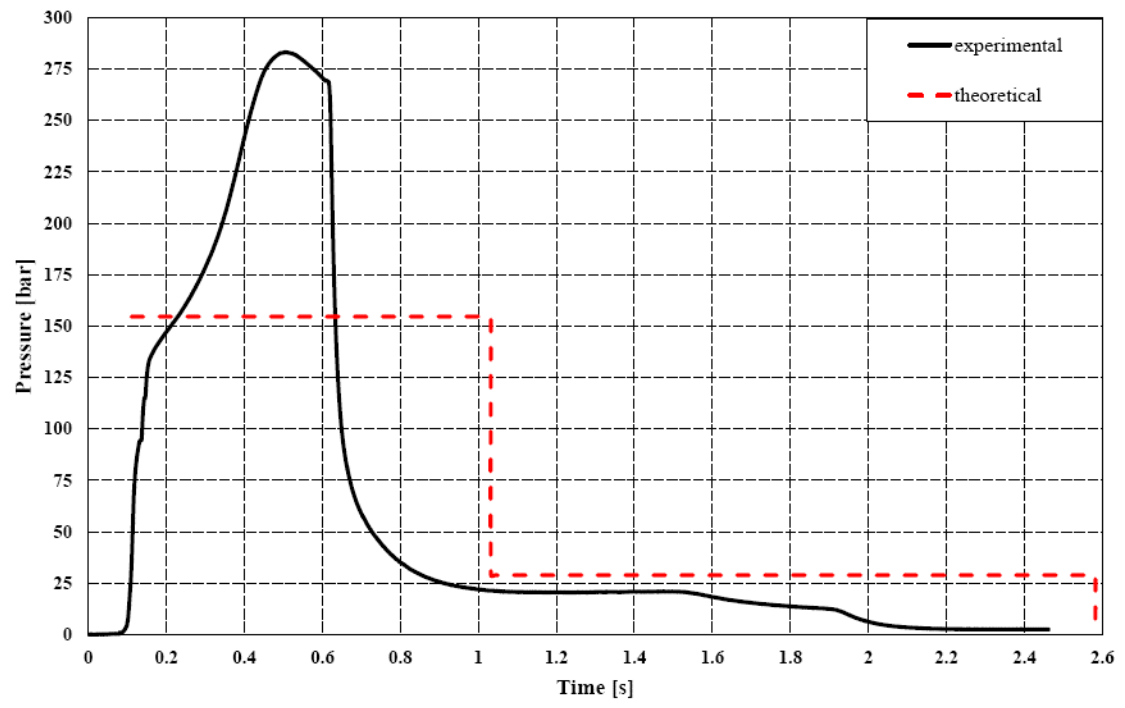

Figure 10 Boosting chamber pressure-time profile for the repeated firing test

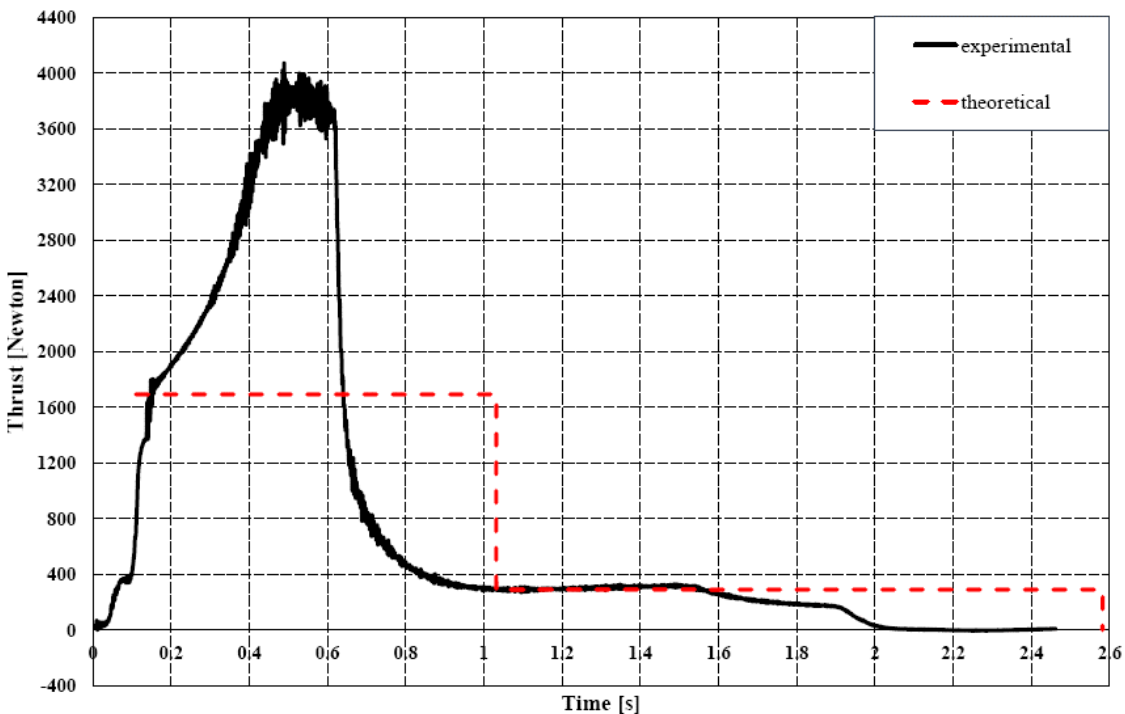

Figure 11 Thrust-time profile for the repeated firing test

Pressure-time curves of the sustaining chamber from the experiment and the corresponding theoretical prediction are shown in Fig. 6. The theoretical curve appears constant at operating pressure 154.5 bar taking a time of operation of about 1.03 seconds then sharply fall down to 102 bar of a constant operating pressure during the sustaining phase which terminates at 2.58 seconds. In contrast, the experimental curve ascends sharply in approximately 0.1 seconds during the ignition phase. The boosting phase starts operating at 150 bar that increases sharply to about 450 bar and lasts for nearly 0.7 seconds operating time then the sustaining phase operates at approximately average pressure of 82 bar till the propellant burnout at 1.7 seconds operating time. Looking at the tail-off phase, the measured pressure decreases sharply in about 0.12 seconds as the propellant grain is burned out.

Figure 7 shows the pressure-time curves of the boosting chamber for the experimental measurement and theoretical prediction. The theoretical curve starts with a constant operating pressure 154.5 bar taking 1.03 seconds operating time during the boosting phase then sharply falls down to 28.85 bar of a constant operating pressure during the sustaining phase which terminates at 2.58 seconds. In the experimental reading, the boosting phase starts operating at 116 bar that increases sharply to about 306 bar and lasts for nearly 0.6 seconds operating time 
then the sustaining phase operates at a nearly constant pressure of 15.5 bar till the propellant burnout at 1.82 seconds operating time.

Finally, the theoretical and experimental thrust-time curves are shown in Fig. 8. The theoretical thrust-time curve appears constant at $1692.8 \mathrm{~N}$ during the boosting phase time of 1.03 seconds. In the sustaining phase, the thrust falls down to $290.4 \mathrm{~N}$ and terminates after 2.58 second. In the boosting phase of the experiment, the thrust increases sharply from 1750 $\mathrm{N}$ to about $4500 \mathrm{~N}$ for 0.6 seconds while the sustaining phase produces $250 \mathrm{~N}$ thrust for 1.15 seconds of operating time. Figures 10 to 12 have the same trend similar to figures 7 to 9 respectively.

The sharp and high increase of the pressure in the sustaining chamber is due to the reverse flow of the combustion gases from the boosting chamber to the sustaining chamber which was not accounted for in the theoretical model calculations. To improve the experimental values due to the reverse flow in the intermediate nozzle, another two modified tests are conducted, the first modified test is designed where the pressure $\left(P_{s, b}\right)$ in the sustaining chamber is slightly less than the pressure $\left(P_{b, b}\right)$ in the boosting chamber. The second modified one is designed where the pressure $\left(P_{s, b}\right)$ in the sustaining chamber is approximately equal the pressure $\left(P_{b, b}\right)$ in the boosting chamber. This is achieved with some modifications to the grains and nozzles dimensions of the basic test. The length of the boosting grain is decreased and the critical diameter of the main and intermediate nozzles are slightly increased such that the condition in equation (1) is still valid. Grains and nozzles dimensions for the modified cases are listed in tables 3 and 4 for the first and second modified tests respectively. The pressure and thrust time curves for TRM are presented in figures 13 to 15 for the first modified test and figures 16 to 18 for the second one.

Table 3 Grains and nozzles dimensions for the first modified DTRM

\begin{tabular}{|l|c|}
\hline \multicolumn{1}{|c|}{ Name } & Value \\
\hline Sustaining grain (outer diameter x its length) $[\mathrm{mm}]$ & $110 \times 25$ \\
\hline Boosting grain (outer diameter x inner diameter x its length) $[\mathrm{mm}]$ & $63.6 \times 24.6 \times 101$ \\
\hline Main nozzle (throat diameter x exit diameter) $[\mathrm{mm}]$ & $9.7 \times 20$ \\
\hline Intermediate nozzle (throat diameter) $[\mathrm{mm}]$ & 5.7 \\
\hline
\end{tabular}

Table 4 Grains and nozzles dimensions for the second modified DTRM

\begin{tabular}{|l|c|}
\hline \multicolumn{1}{|c|}{ Name } & Value \\
\hline Sustaining grain (outer diameter $\mathrm{x}$ its length) $[\mathrm{mm}]$ & $110 \times 25$ \\
\hline Boosting grain (outer diameter $\mathrm{x}$ inner diameter $\mathrm{x}$ its length) $[\mathrm{mm}]$ & $63.6 \times 24.6 \times 101$ \\
\hline Main nozzle (throat diameter x exit diameter) $[\mathrm{mm}]$ & $9.8 \times 20$ \\
\hline Intermediate nozzle (throat diameter) $[\mathrm{mm}]$ & 5.7 \\
\hline
\end{tabular}

Figure 12 shows the pressure-time curves of the sustaining chamber for the experimental reading and theoretical prediction. The theoretical curve appears constant at operating pressure 113 bar for 1.14 seconds operating time then sharply falls down to a constant value of about 78.5 bar during the sustaining phase which terminates at 2.69 seconds. In the experimental curve, the boosting phase starts operating at 90 bar that increases gradually to about 103 bar and lasts for nearly 1.25 seconds operating time. Then, the sustaining phase operates at a nearly average pressure of 65 bar till the propellant burnout at 3 seconds operating time. 
Figure 13 shows the pressure-time curves of the boosting chamber for the experimental measurements and theoretical prediction. The theoretical curve starts with a constant operating pressure of 113 bar taking 1.14 seconds operating time during the boosting phase then sharply falls down to the constant value of 27 bar during the sustaining phase which lasts for 2.69 seconds. In the experimental reading, the boosting phase starts operating at 71 bar that increases gradually to about 73 bar and lasts for 1.5 seconds operating time then the sustaining phase operates at a nearly constant pressure of 15 bar till the propellant burnout at 3 seconds operating time.

Finally, the thrust-time curves of this case are shown in Fig. 14. The theoretical thrusttime curve appears constant at $1303 \mathrm{~N}$ during the boosting phase time of 1.14 seconds. In the sustaining phase, the thrust fall down to $288.8 \mathrm{~N}$ and terminates after 2.69 seconds. In the boosting phase of the experiment, the thrust increases gradually from $900 \mathrm{~N}$ to about $1010 \mathrm{~N}$ for 1.3 seconds while the sustaining phase produces $150 \mathrm{~N}$ thrust for 1.7 seconds of operating time.

Figure 15 shows the pressure-time curves of the sustaining chamber for the experimental reading and theoretical prediction. The theoretical curve appears constant at operating pressure 125.5 bar for 1.145 seconds operating time then sharply falls down to a constant value of about 78.5 bar during the sustaining phase which terminates at 2.67 seconds. In the experimental curve, the boosting phase starts operating at 90 bar that increases gradually to about 95 bar and lasts for nearly 1.3 seconds operating time. Then, the sustaining phase operates at a nearly average pressure of 60 bar till the propellant burnout at 3.1 seconds operating time.

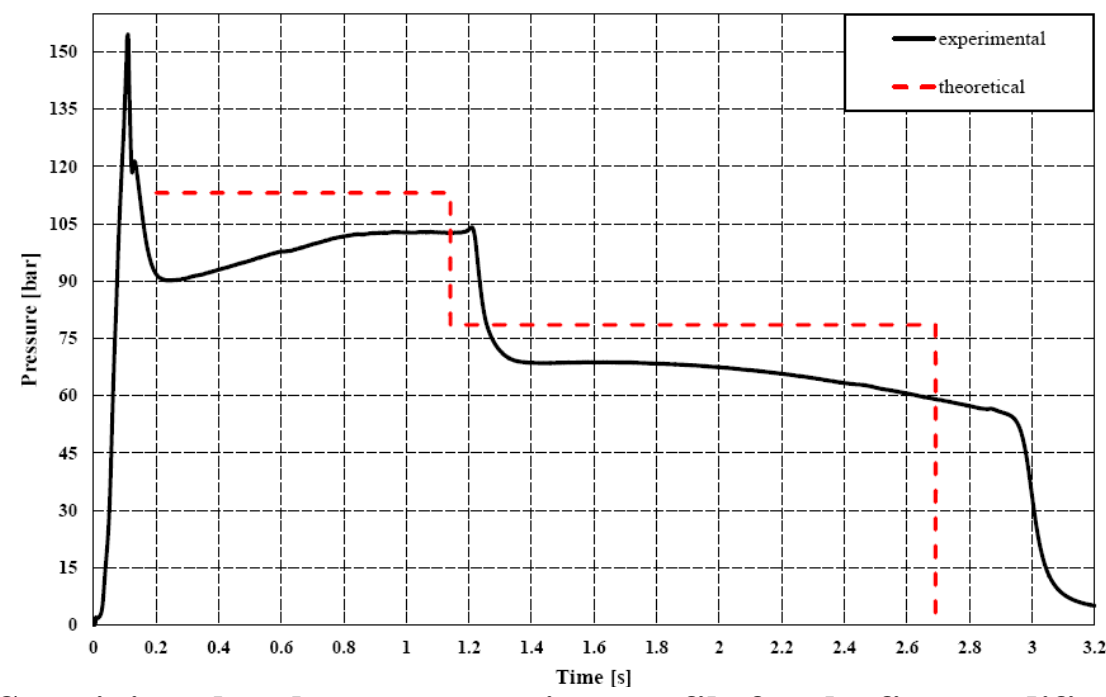

Figure 12 Sustaining chamber pressure-time profile for the first modified firing test 


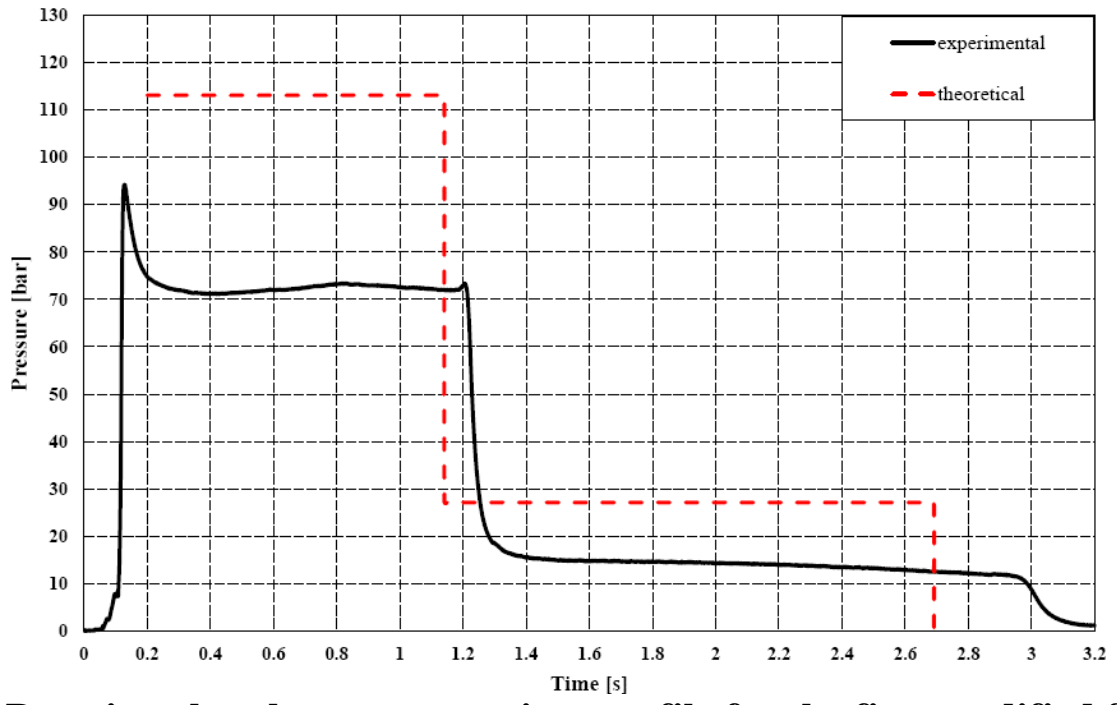

Figure 13 Boosting chamber pressure-time profile for the first modified firing test

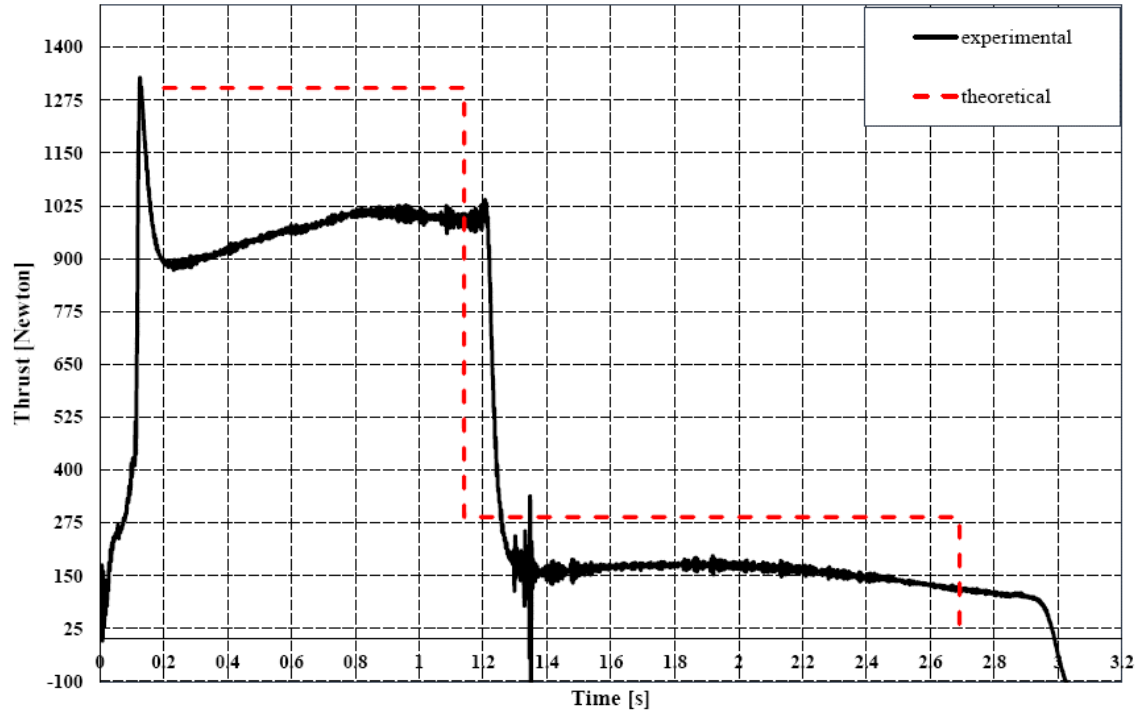

Figure 14 Thrust-time profile for the first modified firing test

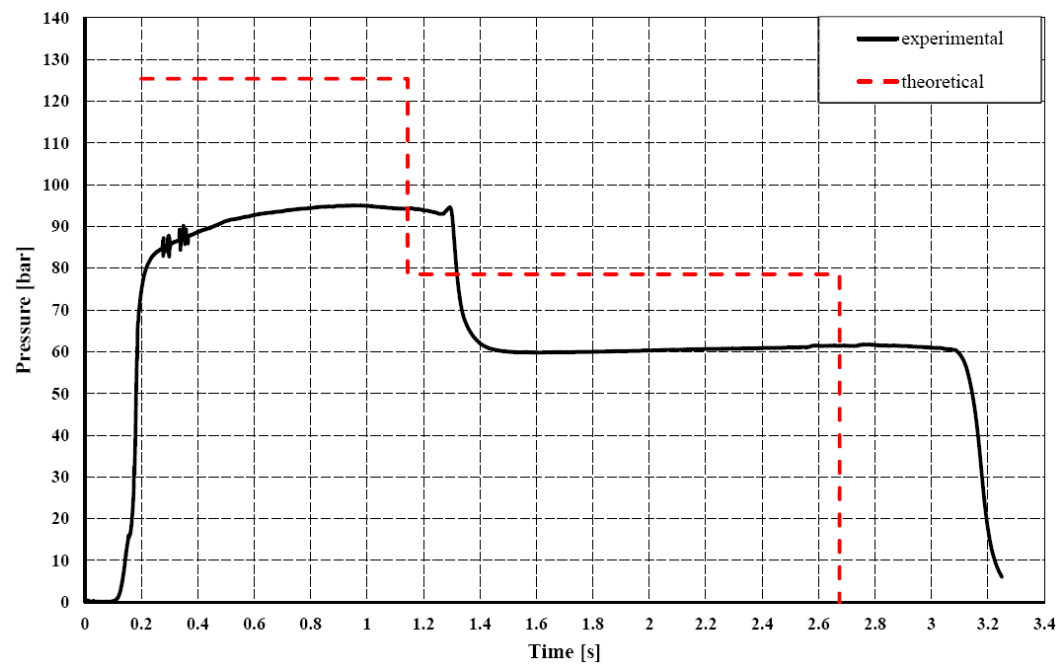

Figure 15 Sustaining chamber pressure-time profile for the second modified firing test 


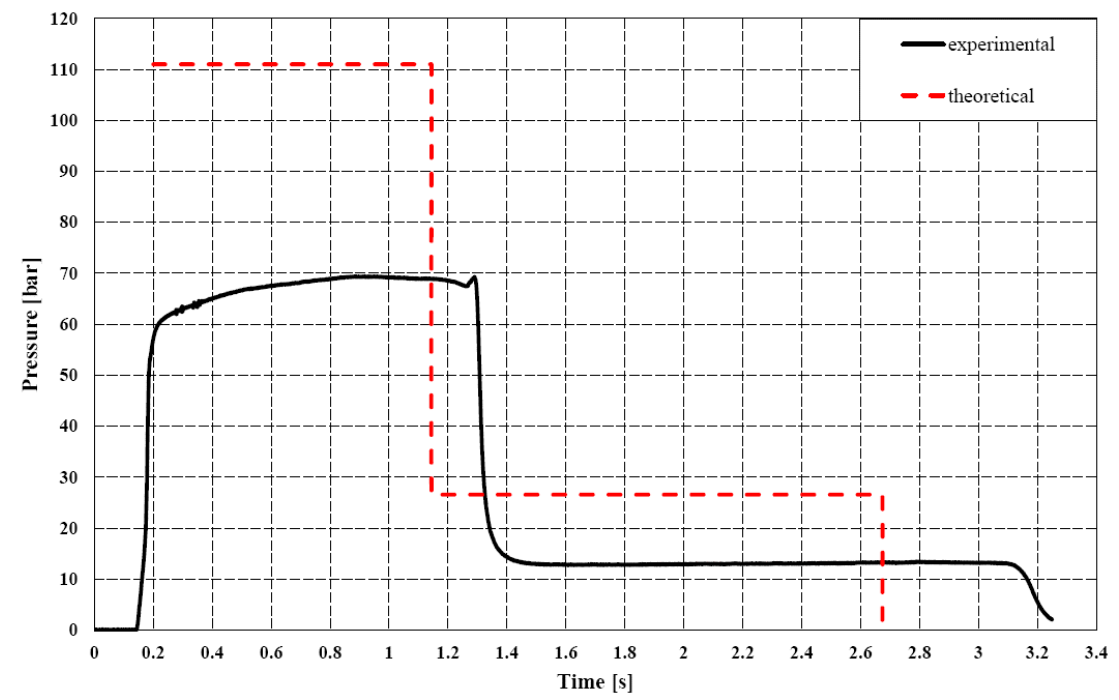

Figure 16 Boosting chamber pressure-time profile for the second modified firing test

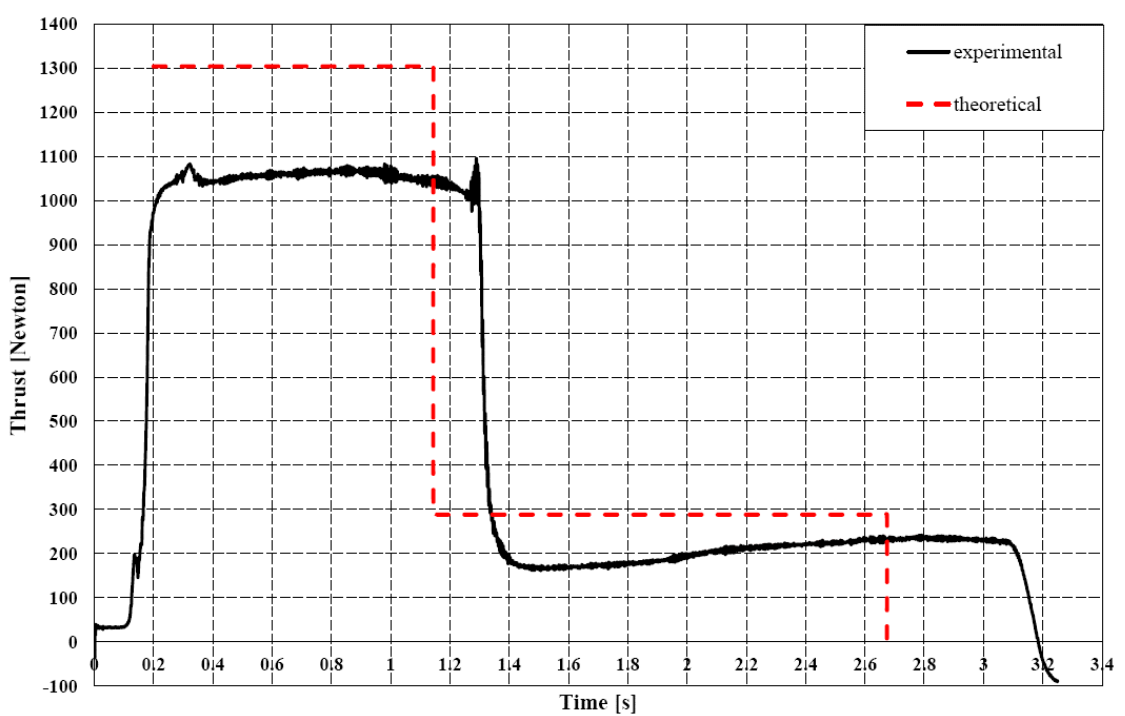

Figure 17 Thrust-time profile for the second modified firing test

Figure 16 shows the pressure-time curves of the boosting chamber for the experimental measurements and theoretical prediction. The theoretical curve starts with a constant operating pressure of 110 bar taking 1.145 seconds operating time during the boosting phase then sharply falls down to the constant value of 26.57 bar during the sustaining phase which lasts for 2.67 seconds. In the experimental reading, the boosting phase starts operating at 63 bar that increases gradually to about 70 bar and lasts for 1.3 seconds operating time then the sustaining phase operates at a nearly constant pressure of 13 bar till the propellant burnout at 3.1 seconds operating time.

Finally, the thrust-time curves of this case are shown in Fig. 17. The theoretical thrusttime curve appears constant at $1303 \mathrm{~N}$ during the boosting phase time of 1.145 seconds. In the sustaining phase, the thrust fall down to $288.2 \mathrm{~N}$ and terminates after 2.67 seconds. In the boosting phase of the experiment, the thrust increases gradually from $1035 \mathrm{~N}$ to about $1080 \mathrm{~N}$ for 1.3 seconds while the sustaining phase produces $165 \mathrm{~N}$ thrust for 1.8 seconds of operating time.

As shown in figures 6, 9, 12 and 15, the differentiation between the boosting and sustaining phases are clear. In figures 6 and 9, due to the significant pressure difference between the sustaining and boosting chambers and the reverse flow which occurs, there is a startling increase in the experimental pressure values in the boosting phase cannot be calculated and can easily cause an explosion. In Fig. 12, where the boosting pressure is only 
slightly higher than that of the sustaining pressure, there is no sever reverse flow and the pressure of the sustaining chamber is only slightly increased. So, the experimental pressure values improved perfectly than that in figures 6 and 9 after the modification is made. In Fig. 15 , where the boosting pressure is approximately equal to the sustaining pressure, there is a slight difference between the theoretical and experimental pressure values. The experimental pressure data has lower values than the theoretical approach due to the losses in the TRM and the isentropic assumption of the theoretical investigation that explained earlier.

Also in figures 7, 10, 13 and 16, the differentiation between the two phases is clear. By similarity, figures 7 and 10 have the same trend of figures 6 and 9. It is also clear that there is a steady fall between theoretical approach and experimental one. It can be seen also that this pressure-time trend in figures $7,10,13$ and 16 yields the thrust time trends shown in figures $8,11,14$ and 17, respectively. The TRM produces a thrust ratio 18 for the basic and repeated test and approximately 7 for the modified tests.

In figures 13 and 16, it is apparent that the experimental results improved and became smoother in comparison with the data listed in figures 7 and 10. Comparing the approaches (experimental and theoretical) in figures 13 and 16, it can be seen that the experimental boosting chamber pressures is almost always less than the theoretical one.

\section{Conclusions:}

The objective of the present study was to understand the physics of internal ballistics of DTRM in the specific case where the reverse flow takes place through the intermediate nozzle.

A mathematical model has been developed and a set of static firing tests have conducted in a specially-designed TRM. The main conclusions of this study are as follows:

1. DTRM with $\left(P_{s, b} \ll P_{b, b}\right)$ induced a strong reverse flow. This strong flow causes dramatic increase in the sustaining chamber pressure.

2. The modified static tests $\left(P_{s, b} \leq P_{b, b}\right)$ or $\left(P_{s, b} \approx P_{b, b}\right)$ gave considerable high thrust ratio $(\approx 7)$, but the thrust was smooth and good agreement with the computed results is noticed.

3. The four tests shows that the best design regime of this case is done when $\left(P_{s, b} \approx P_{b, b}\right)$.

The present study can be extended in view of investigating theoretically the transient case of the reverse flow through the intermediate nozzle.

\section{References:}

[1] G. Sutton, Rocket Propulsion Elements, seventh ed.: JOHN WILEY \& SONS, INC., 2001

[2] H. M. Darwell, "Solid Propellant Dual-Thrust Motors," Proceeding of the 1st Rocket Propulsion Symposium, 1961.

[3] McFillin, J. F., Van Brocklin, S. T., Beakley, J. E., and Netzer, D. W., "Dual-Chamber Roicekt Motor Operating Characteristics," Journal of Space Craft and Rockets, Vol. 21, No. 2, 1984, pp. 168- 174.

[4] Carrier, J. L., Constantinou, T., Harris, P. G., and Smith, D. L., "Dual-InterruptedThrust Pulse Motor," Journal of Propulsion and Power, Vol. 3, No. 4, 1987, pp. 308312.

[5] Manda, L. J., "Boost-Phase Equilibrium Pressures in a Dual-Thrust Soil-Propellant Rocket Motor," Journal of Spacecraft and Rockets, Vol. 2, No. 4, 1965, pp.607-609.

[6] M. Barrerre, Rocket Propulsion: Elsevier Pub. Co., 1960.

[7] B. P. Dunn. (2013, Cited Jan. 2013). "Rocket Engine Specific Impulse Program," http://www.dunnspace.com/isp.htm. 